\title{
RGD-conjugated gold nanorods induce radiosensitization in melanoma cancer cells by downregulating $\alpha_{v} \beta_{3}$ expression
}

This article was published in the following Dove Press journal:

International Journal of Nanomedicine

23 February 2012

Number of times this article has been viewed

\author{
Wencai Xu' \\ Teng Luo ${ }^{2}$ \\ Ping $\mathrm{Li}^{1}$ \\ Chuanqing Zhou ${ }^{2}$ \\ Daxiang Cui ${ }^{3}$ \\ Bo Pang ${ }^{4}$ \\ Qiushi Ren ${ }^{4}$ \\ Shen Fu' \\ 'Department of Radiation Oncology, \\ Shanghai Sixth People's Hospital, \\ ${ }^{2}$ School of Biomedical Engineering, \\ and ${ }^{3}$ National Key Laboratory of \\ Nano/Micro Fabrication Technology, \\ Key Laboratory for Thin Film and \\ Microfabrication of Ministry of \\ Education, Institute of Micro-Nano \\ Science and Technology, Shanghai \\ Jiao Tong University, Shanghai, \\ ${ }^{4}$ Department of Biomedical \\ Engineering, College of Engineering, \\ Peking University, Beijing, People's \\ Republic of China
}

Background: Melanoma is known to be radioresistant and traditional treatments have been intractable. Therefore, novel approaches are required to improve the therapeutic efficacy of melanoma treatment. In our study, gold nanorods conjugated with Arg-Gly-Asp peptides (RGD-GNRs) were used as a sensitizer to enhance the response of melanoma cells to $6 \mathrm{mV}$ radiation.

Methods and materials: A375 melanoma cells were treated by gold nanorods or RGD-GNRs with or without irradiation. The antiproliferative impact of the treatments was measured by MTT assay. Radiosensitizing effects were determined by colony formation assay. Apoptosis and cell cycle data were measured by flow cytometry. Integrin $\alpha_{v} \beta_{3}$ expression was also investigated by flow cytometry.

Results: Addition of RGD-GNRs enhanced the radiosensitivity of A375 cells with a dosemodifying factor of 1.35, and enhanced radiation-induced apoptosis. DNA flow cytometric analysis indicated that RGD-GNRs plus irradiation induced significant G2/M phase arrest in A375 cells. Both spontaneous and radiation-induced expressions of integrin $\alpha_{v} \beta_{3}$ were downregulated by RGD-GNRs.

Conclusion: Our study indicated that RGD-GNRs could sensitize melanoma A375 cells to irradiation. It was hypothesized that this was mainly through downregulation of radiationinduced $\alpha_{\mathrm{v}} \beta_{3}$, in addition to induction of a higher proportion of cells within the G2/M phase. The combination of RGD-GNRs and radiation needs further investigation.

Keywords: radiosensitivity, melanoma, Arg-Gly-Asp peptides, gold nanorods, integrin $\alpha_{\mathrm{v}} \beta_{3}$, G2/M arrest

\section{Introduction}

Radiation therapy is one of the commonly utilized treatments for cancer. However, local failure after irradiation remains a challenge due to intrinsic and acquired resistance of tumor cells to radiation treatment. Radiation not only eradicates tumor cells through DNA damage and apoptosis, but also influences cell adhesion to the extracellular matrix by regulating receptors such as integrins. ${ }^{1}$

Integrins are composed of a single alpha and a single beta chain that have activated or nonactivated conformations. There are eight known beta subunits and 18 alpha subunits that can be combined to form over 24 known mammalian integrins. ${ }^{2}$ A substantial body of data support the view that integrins, such as $\alpha_{\mathrm{v}} \beta_{3}$, play a critical role in regulating tumor growth and metastasis as well as tumor angiogenesis. ${ }^{3,4}$ $\alpha_{\mathrm{v}} \beta_{3}$ is expressed on the surface of a variety of cells, including endothelial cells and certain tumor cells in human malignant melanoma, breast cancer, and advanced 
glioblastoma. ${ }^{4}$ Integrin $\alpha_{\mathrm{v}} \beta_{3}$ expression not only affects tumor radiosensitivity, ${ }^{5}$ but is also associated with acquired radioresistance through the upregulation of integrin expression by radiation. ${ }^{6,7}$ Therefore, targeting integrin $\alpha_{\mathrm{v}} \beta_{3}$ has received relatively more attention due to its role as a potential target for inhibition of angiogenesis and tumor growth. ${ }^{3}$ Arginine (R)-glycine (G)-aspartate (D) (RGD) is the most effective and widely used peptide sequence for stimulating cell adhesion on synthetic material surfaces. The RGD sequence is present in many extracellular matrix proteins and can interact with integrin receptors at focal adhesion points. Once the RGD sequence is recognized and bound to integrins, it initiates an integrin-mediated cell adhesion process and activates signal transduction between the cell and extracellular matrix, thus influencing cell behavior on the substrate (eg, proliferation, differentiation, apoptosis, survival, and migration). ${ }^{8}$ Cyclic RGD-containing pentapeptides, such as cilengitide, are the most commonly used integrin $\alpha_{v} \beta_{3}$ inhibitors and enhance the response of different cancer cells to irradiation..$^{9,10}$

Although it is anticipated that RGD peptides will be very promising as radiosensitizers, success in enhancing the radiotherapeutic ratio for cancer depends on increasing tumor cytotoxicity while simultaneously reducing harmful effects on normal tissues. An ideal strategy would be to identify a radiosensitizer that preferentially and effectively enhances the process of radiation-induced cell death in tumor cells which can be coupled with a delivery system that will increase inhibition of tumor tissues in a targeted way without affecting normal tissue. Recently, there have been efforts to develop a nanomedicine that actively targets cancer cells and contains effective anticancer drugs to exploit cancer-specific molecular targets. ${ }^{11}$ Nanotechnology is an emerging technique for improved cellular targeting and radiosensitization. Gold nanorods are widely used as delivery vehicles to carry chemotherapeutic agents or radiosensitizers to malignant cells in the treatment of cancer. ${ }^{12}$ Gold nanorods have low cytotoxicity, robust stability, biocompatibility, and suitable physiochemical parameters, and some studies have reported that gold nanorods functionalized with drug molecules show substantially expanded performance as efficient therapeutic drug carriers. The use of structurally modified gold nanorods is less toxic to normal tissue during delivery, and at the molecular level, could traverse biologic barriers and preferentially accumulate in cancer cells. ${ }^{13,14}$ Achieving the development of a competent cancer nanomedicine may bring new hope to cancer patients.

The present study investigated the benefit of combining RGD-conjugated gold nanorods (RDG-GNRs) that target integrin $\alpha_{\mathrm{v}} \beta_{3}$ with irradiation in melanoma cancer cells, and also considered some possible mechanisms for the radiosensitizing effects of RGD-GNRs.

\section{Materials and methods Preparation of RGD-GNRs}

The gold nanorods were synthesized using the seed-mediated template-assisted protocol, ${ }^{15,16}$ by reducing gold salt in the presence of surfactant-directed synthesis. First, a $20 \mathrm{~mL}$ aliquot of gold nanorod stock solution (Sinopharm Chemical Reagent Co, Shanghai, China) was centrifuged and redispersed in $20 \mathrm{~mL}$ deionized water (Millipore, Shanghai, China). Then, $1.1 \mathrm{~mL}$ of $10 \mathrm{mM}$ tetraethyl orthosilicate ethanol solution (J \& K Chemical Ltd, Shanghai, China) was added to the $20 \mathrm{~mL}$ of aqueous gold nanorods ( $\mathrm{pH}$ adjusted to $10-11$ by $\mathrm{NH}_{4} \mathrm{OH}$ ). After vigorous stirring for 10 hours at room temperature, an approximately $31 \mathrm{~nm}$ thick silica layer formed on the surface of the gold nanorods through hydrolysis and condensation of tetraethyl orthosilicate. ${ }^{17}$ The silica-coated nanoparticles were isolated by centrifugation, washed with deionized water and ethanol several times, and then dispersed in deionized water for later use. To create molecularly targeted particles, the gold nanorod surfaces were modified by cycle RGD peptides (Shanghai, China) using the standard EDC-NHS reaction as described by Johnsson et al. ${ }^{18} \mathrm{~A}$ solution of RGD in deionized water was added to a volume of silica-coated gold nanorods to react for 48 hours and excess RGD peptides were removed by centrifugation at $6000 \mathrm{rpm}$ for 15 minutes. The RGD-GNRs were dispersed in Dulbecco's Modified Eagle Medium (Hyclone, Carlsbad, CA) and stored at $4{ }^{\circ} \mathrm{C}$ for later cell experiments.

\section{Cell lines and culture}

Human melanoma A375 cells were purchased from the Shanghai Institute of Cell Biology and Chinese Academy of Sciences (Shanghai, China) and grown in flasks containing Dulbecco's Modified Eagle Medium with 10\% heat-inactivated fetal bovine serum (Hyclone). Cells were incubated at $37^{\circ} \mathrm{C}$ in a humidified atmosphere with $50 \mathrm{~mL} / \mathrm{L} \mathrm{CO}_{2}$.

\section{Transmission electron microscopic analysis of cells with internalized gold nanorods}

A375 cells previously incubated with RGD-GNRs were washed three times with phosphate-buffered saline and fixed with $2.5 \%$ glutaraldehyde for six hours. The cells were postfixed in $1 \%$ osmium tetroxide for 2 hours, dehydrated in ethanol, and embedded in agar resin (Agar Scientific, 
Stansted, Essex, UK). Thin sections (60-70 nm) were collected on copper grids, stained with methanol and lead citrate, and visualized using transmission electron microscopy (Philips CM120).

\section{Cellular proliferation assay}

Exponentially growing cells were incubated in six-well culture dishes in the presence of RGD-GNRs or gold nanorods alone at different concentrations for a series of times. Then, $15 \mu \mathrm{L}$ of MTT solution $(5 \mathrm{mg} / \mathrm{mL}$; Sigma-Aldrich, Shanghai, China) was added to each well and the cells were incubated for 4 hours. The reaction was stopped by removal of MTT, and $100 \mu \mathrm{L}$ of dimethylsulfoxide (Sigma-Aldrich) was added to each well to dissolve the formazan crystals, then plates were read at $570 \mathrm{~nm}$. All experiments were repeated three times and measurements were done in triplicate.

\section{Irradiation}

Cells in a monolayer were irradiated using $6 \mathrm{mV}$ x-rays from linear accelerators (Siemens, Münich, Germany) at a dose rate of $3 \mathrm{~Gy} /$ minute at room temperature. A $1.5 \mathrm{~cm}$ bolus was used as a compensator.

\section{Clonogenic assay}

A total of about $5 \times 10^{5}$ cells were first seeded and grown in six-well culture plates for 24 hours, and then incubated with RGD-GNRs or gold nanorods alone $(50 \mu \mathrm{g} / \mathrm{mL})$ for one hour prior to irradiation. Next, the cells were detached, seeded, and grown in six-well culture plates for 2 weeks to form colonies. The colonies were stained with $0.4 \%$ crystal violet and the count of colonies containing $>50$ cells was used for the calculation of the surviving fraction (SF). Values were expressed as the mean \pm standard deviation. All experiments were repeated three times. Survival curves were fitted to a LQ model using Graphpad Prism software (version 5.0). Survival fraction at $2 \mathrm{~Gy}$ (SF2) and dose-modifying factor values were used to quantify the radiosensitizing effect of the cells.

\section{Cell cycle and apoptosis assays by flow cytometry}

A 375 cells $\left(10^{6}\right.$ cells $\left./ \mathrm{mL}\right)$ fixed in $95 \%$ ethanol at $-20^{\circ} \mathrm{C}$ for 24 hours were washed with cold phosphate-buffered saline, resuspended, and stained with propidium iodide $(50 \mu \mathrm{g} / \mathrm{mL}$ phosphate-buffered saline; Invitrogen, Shanghai, China) for 15 minutes at $4{ }^{\circ} \mathrm{C}$. Analysis was performed using a FACSCalibur flow cytometer (Becton-Dickinson, Franklin Lakes, NJ). Cellular DNA content and cell cycle data were analyzed by flow cytometry using multicycle system
2.0 software. For the apoptosis assay, the cells were stained with Annexin-V-fluorescein isothiocyanate/propidium iodide (Invitrogen) and measured by flow cytometry. All tests were repeated three times.

\section{Integrin $\alpha_{\mathrm{v}} \beta_{3}$ analysis}

A375 cells were collected and suspended in phosphatebuffered saline $/ 0.2 \%$ bovine serum albumin at a concentration of $10^{6}$ cells $/ \mathrm{mL}$. A $200 \mu \mathrm{L}$ sample of the suspension was incubated with a mouse antihuman integrin $\alpha_{\mathrm{v}} \beta_{3} \mathrm{mAb}$ LM609 (Millipore, Shanghai, China) or isotype-matched control antibody DD7 (Millipore) for 45 minutes at $4{ }^{\circ} \mathrm{C}$. The cells were washed three times with phosphate-buffered saline and analyzed using a FACSCalibur flow cytometer. Specific fluorescence index values were calculated by dividing mean fluorescence obtained with specific Ab by mean fluorescence obtained with isotype control $\mathrm{Ab} .^{19}$

\section{Statistical analysis}

SPSS statistical software (v13.0, SPSS Inc, Chicago, IL) was used for the statistical analyses. The results were expressed as the mean \pm standard deviation. One-way analysis of variance was performed to compare the means between two test groups, with a $P$ value $\leq 0.05$ considered to be statistically significant.

\section{Results Cellular toxicity and uptake of RGD- GNRs by A375 cells}

Gold nanoparticles were stabilized and grown to linear gold nanorods with the assistance of a reversible adsorption-desorption process of high concentrations of cetyltrimethylammonium bromide (CTAB) surfactant in a reaction medium. However, CTAB-coated gold nanorods (length $44.44 \pm 4.7 \mathrm{~nm}$; width $15.10 \pm 1.7 \mathrm{~nm}$ ) do not open any available sites for surface modification and CTAB showed high cell toxicity. For silica coating (thickness about $31 \mathrm{~nm}$, Figure $1 \mathrm{~A}$ and B), surfaceoccupying $\mathrm{CTAB}$ was washed away via multiple centrifugeprecipitation processes. ${ }^{20}$ The structures of the gold nanorods and the cellular uptake of RGD-GNRs were visualized using transmission electron microscopy. After the A375 cells were incubated with RGD-GNRs for one hour, RGD-GNRs could be located both on the surface of the cell membranes and internalized into A375 cells via integrin $\alpha_{\mathrm{v}} \beta_{3}$-receptor-mediated endocytosis $^{21,22}$ (Figure 1C and D). MTT assays showed that both the gold nanorods and RGD-GNRs had antiproliferative effects in a dose-dependent manner and that RGD-GNRs were significantly $(P<0.05)$ more toxic to the cells than the 
A

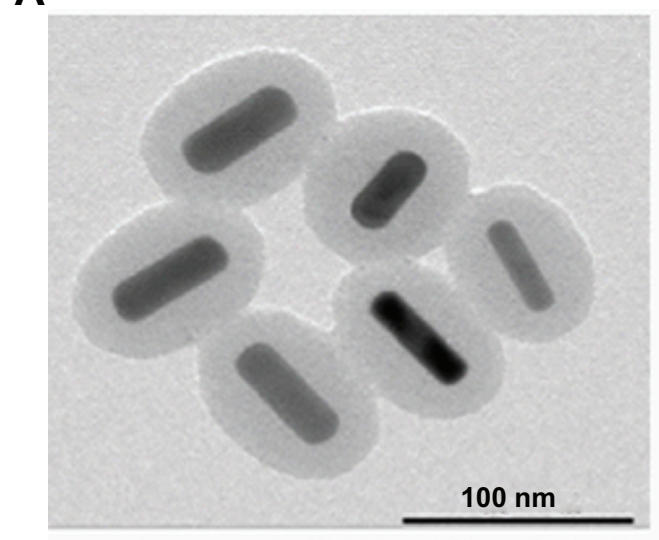

C

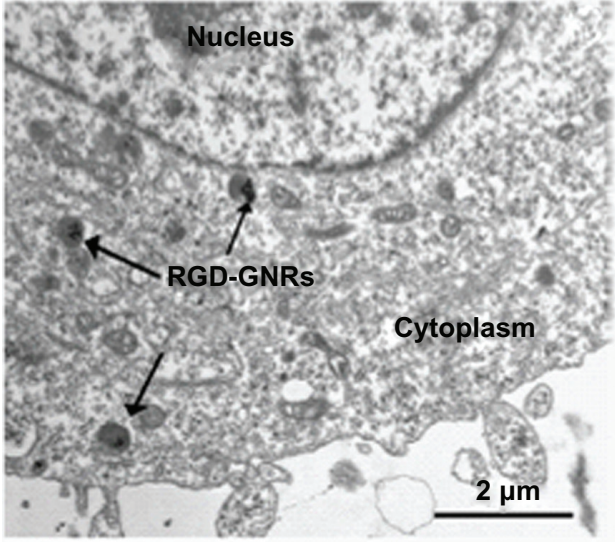

B

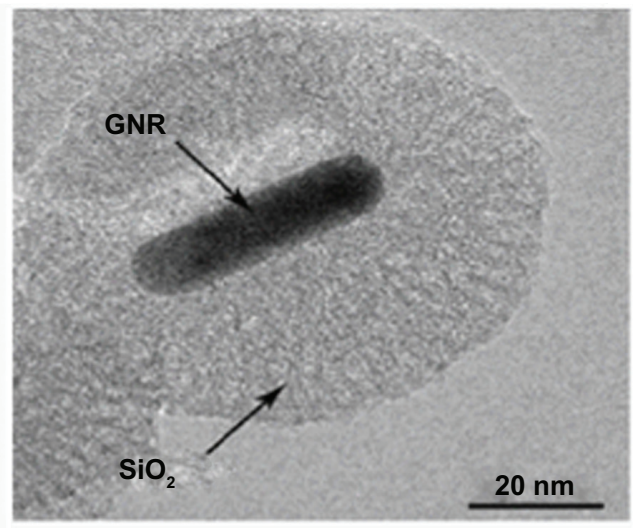

D

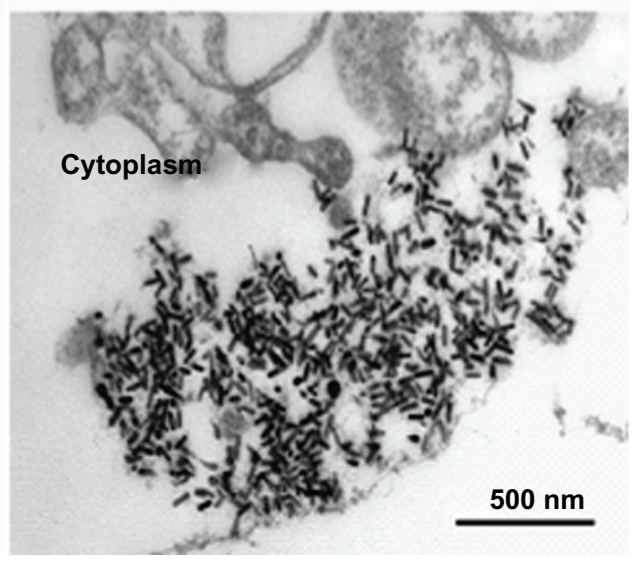

Figure I Gold nanorods and internalization by human melanoma A375 cells. (A and B) Nanoparticles shown at different magnifications as viewed by transmission electron microscopy. The gold nanorods were coated with an approximately $31 \mathrm{~nm}$ silica layer. (C and D) A375 melanoma cell shows evidence of internalized RGD-GNRs. Gold nanorods were internalized into cells by endocytosis at the cell membrane, and mainly distributed in cytoplasm.

Abbreviations: GNR, gold nanorod; RGD-GNRs, arginine-glycine-aspartate-conjugated gold nanorods.

gold nanorods (Figure 2A). To evaluate the ability of gold nanorods and RGD-GNRs to sensitize the cells to radiation, $50 \mu \mathrm{g} / \mathrm{mL}$ of gold nanorods and RGD-GNRs that were slightly toxic after 24 hours in culture (Figure 2B) were used for the radiosensitization experiments.

\section{Radiosensitization of melanoma cells by RGD-GNRs}

A colony formation assay was used to compare the radiosensitizing effect of gold nanorods and RGD-GNRs in melanoma cells. The dose-response curves of the cells are shown in Figure 3. After irradiation treatment in combination with either gold nanorods or RGD-GNRs, the radiosensitizing effect was quantified by a dose-modifying factor based on the survival fraction at $2 \mathrm{~Gy}$. Both gold nanorods alone and RGD-GNRs enhanced the radiosensitivity of A375 cells to $6 \mathrm{mV}$ x-rays with a dose-modifying factor (SF2) of 1.14 and 1.35 , respectively. These differences were statistically significant compared with radiation alone $(P<0.05)$. One-way analysis of variance shows that more radiosensitization was observed for cells containing RGD-GNRs compared with cells containing gold nanorods alone $(P=0.001)$.

\section{Enhanced radiation-induced apoptosis by RGD-GNRs in melanoma cells}

The percentages of A375 cells in apoptosis after the various treatments are shown in Figure 4. Cellular incorporation of gold nanorods alone or RGD-GNRs did not significantly increase the amount of cell apoptosis compared with controls. Radiation alone or combined with gold nanorods slightly enhanced apoptosis $(4.97 \% \pm 0.83 \%$ and $7.67 \% \pm 0.31 \%$, respectively); there was a statistically significant difference between treated and untreated cells $(2.23 \% \pm 0.42 \%, P<0.05)$. However, cells treated with RGD-GNRs plus radiation underwent significantly $(P<0.05)$ more apoptosis $(15.10 \% \pm 0.96 \%)$ compared with other cells.

\section{Enhancement of radiation-induced G2 cell cycle arrest by RGD-GNRs}

Because the radiosensitivity of tumor cells is cell cycleoriented, more radiosensitivity was observed in the G2/M 

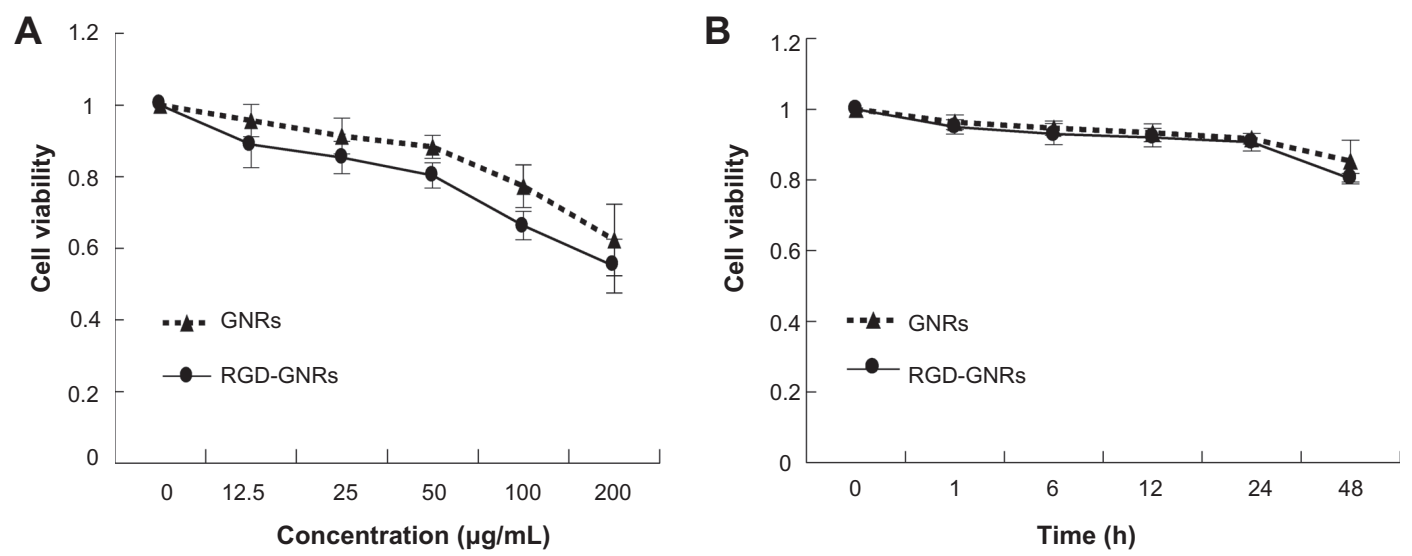

Figure 2 Effects of RGD-GNRs and gold nanorods on cell viability. A375 cells were seeded in 96-well culture plates and incubated in the absence (control) or the presence of the indicated concentrations of gold nanorods or RGD-GNRs for 48 hours (A), or A375 cells were treated with RGD-GNRs or gold nanorods at concentrations of 50 $\mu \mathrm{g} / \mathrm{mL}$ for variable times (B). Cell viability was measured by MTT assay and analyzed using an enzyme-labeling analyzer.

Notes: Data were compared with the control group (normalized I.0) and data points represent the mean survival fraction of three independent experiments done in triplicate; error bars represent the standard deviation.

Abbreviations: GNR, gold nanorod; RGD-GNRs, arginine-glycine-aspartate-conjugated gold nanorods.

phase and less in the G0/G1 or S phase. In Figure 5, treatment of A375 cells with GNRs, RGD-GNRs, or radiation alone ( $6 \mathrm{mV}$ x-rays with a dose of $4 \mathrm{~Gy}$ ) significantly induced cell cycle arrest at the $\mathrm{G} 2 / \mathrm{M}$ phase $(35 \% \pm 2.65 \%$, $36.14 \% \pm 0.35 \%$, and $40.9 \% \pm 0.35 \%$, respectively). There were significant differences compared with the control cells $(25.84 \% \pm 0.49 \% ; P<0.05)$, but not among the single treatment groups. The cells treated with a combination of RGD-GNRs plus radiation further enhanced arrest of the cells at the $\mathrm{G} 2 / \mathrm{M}$ phase $(46.5 \% \pm 1.2 \%)$. One-way analysis of variance has also shown that there were significant

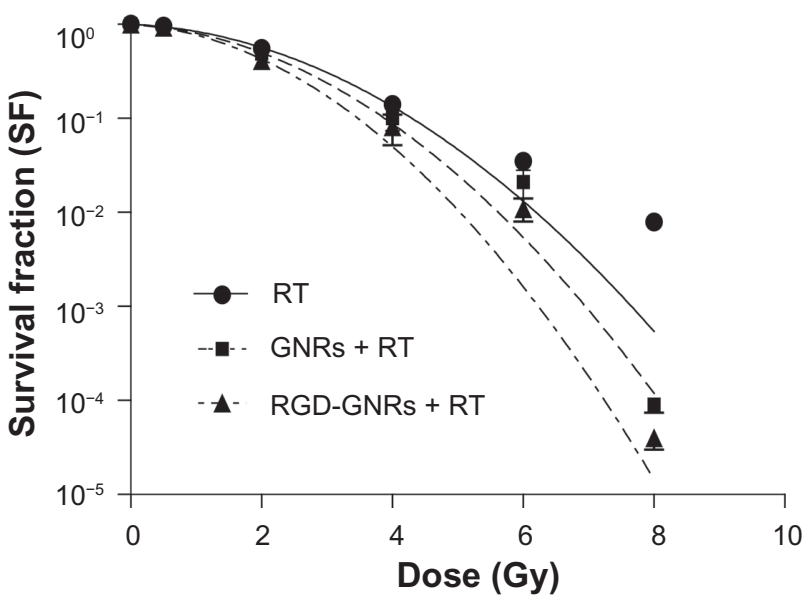

Figure 3 Radiosensitizing effect of gold nanorods or RGD-conjugated gold nanorods. A375 cells were treated with either gold nanorods $(50 \mu \mathrm{g} / \mathrm{mL})$ or RGDGNRs $(50 \mu \mathrm{g} / \mathrm{mL})$ for one hour prior to indicated irradiation. Cells were trypsinized, counted, and seeded at different dilutions. Colonies of $>50$ cells were counted approximately 2 weeks after treatment.

Notes: The clonogenic surviving fractions were generated with each point representing the mean surviving fraction calculated from three independent experiments done in triplicate for each treatment condition; error bars represent the standard deviation. Abbreviations: GNR, gold nanorod; RGD-GNRs, arginine-glycine-aspartate-conjugated gold nanorods; RT, radiotherapy. differences between the RGD-GNRs plus radiation group and both untreated and single treatment groups $(P<0.05)$.

\section{Integrin $\alpha_{\mathrm{v}} \beta_{3}$ expression levels and effect of irradiation and RGD-GNRs}

Radiation induced a significant expression of integrin $\alpha_{\mathrm{v}} \beta_{3}$ in a dose-dependent manner (Figure 6). Incubating the cells with GNRs did not impact the expression of integrin $\alpha_{\mathrm{v}} \beta_{3}$, but RGD-GNRs could effectively reduce the spontaneous expression of integrin $\alpha_{\mathrm{v}} \beta_{3}$ compared with the results of the untreated cells $(P<0.05)$. While the cells incubated with RGD-GNRs one hour prior to radiation at 4 Gy, RGD-GNRs could inhibit both spontaneous and radiation-induced $\alpha_{\mathrm{v}} \beta_{3}$ expression, while untreated or radiation alone could not $(P=0.001)$.

\section{Discussion}

The incidence of melanoma is on the rise worldwide, with an estimated age-standardized incidence rate of 40.2 cases per 100,000 population in $2008 .{ }^{23}$ Melanoma cells are well known to be resistant to radiation, so any new strategies that overcome the relative radioresistance of melanoma tumors could prove to be useful and beneficial to many patients. In the present study, we used gold nanorods as a delivery system and conjugated these to cyclic RGD peptides, an antagonist of integrin $\alpha_{v} \beta_{3}$, to target tumor cells. Since CTAB is a necessary structure-directing agent in the gold nanorod synthesis method, severe cytotoxicity and low stability are still two problems which CTAB-coated gold nanorods need to solve. One of the solutions to these problems is depositing 

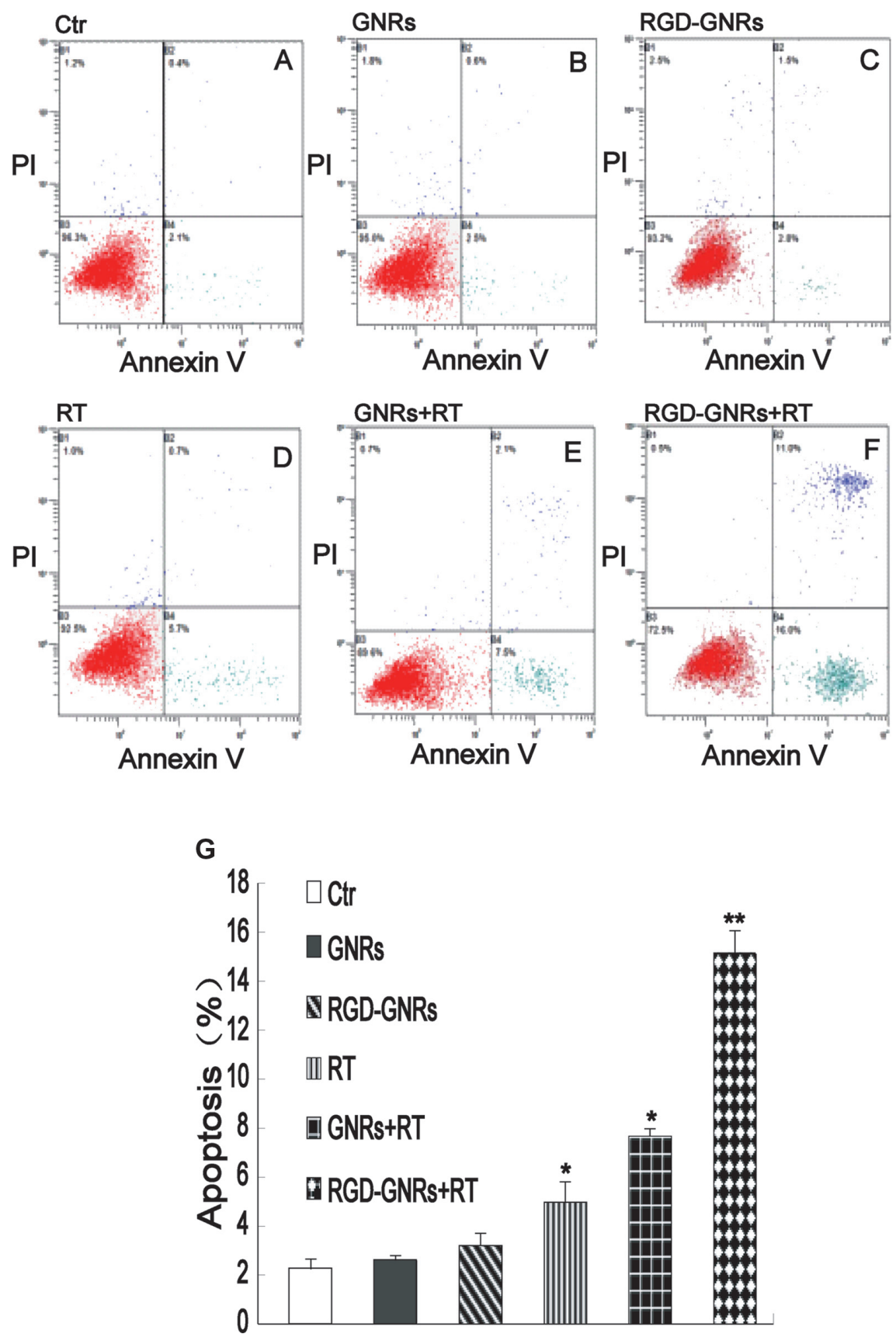

Figure 4 Enhancement of radiation-induced apoptosis by RGD-GNRs. A375 cells were treated with either gold nanorods or RGD-GNRs for one hour prior to irradiation. The cells were stained with Annexin $\mathrm{V}$ and propidium iodide, and apoptosis was analyzed by flow cytometry after 24 hours of treatment. (A-C) Apoptosis in control cells and the cells containing gold nanorods ( $50 \mu \mathrm{g} / \mathrm{mL}$ for 24 hours) or RGD-GNRs (50 $\mu \mathrm{g} / \mathrm{mL}$ for 24 hours) without radiation. (D-F) Apoptosis in radiation alone cells and cells containing gold nanorods or RGD-GNRs plus radiation ( $6 \mathrm{mV}$ x-rays at a dose of $4 \mathrm{~Gy}$ ). (G) Data from (A-F) were quantified and are presented as the mean \pm standard deviation ( $\mathrm{n}=3$ experiments).

Notes: $* P<0.05$ compared with control group; $* * P<0.05$ compared with other treated groups.

Abbreviations: Ctr, Control Group; GNR, gold nanorod; PI, propidium iodide; RGD-GNRs, arginine-glycine-aspartate-conjugated gold nanorods; RT, radiotherapy.

an additional coating on the surface of CTAB-coated gold nanorods. Because silica has been reported to be stable and have low toxicity, it is very suitable for use as a coating material for gold nanorods. ${ }^{24,25}$ Another feature of a silica system is that it is biocompatible and easily modified, so a gold nanorod coating with silica can easily be covalently conjugated with RGD. In this case, RGD-GNRs will recognize $\alpha_{\mathrm{v}} \beta_{3}$ expression-positive tumor cells, be internalized into cells, trapped in endosomes, and degraded within endosome compartments. Therefore, the toxic molecules released by RGD-GNRs will be harmful to the cancer cells that bind to RGD-GNRs. Most normal cells, except for endothelial cells, 

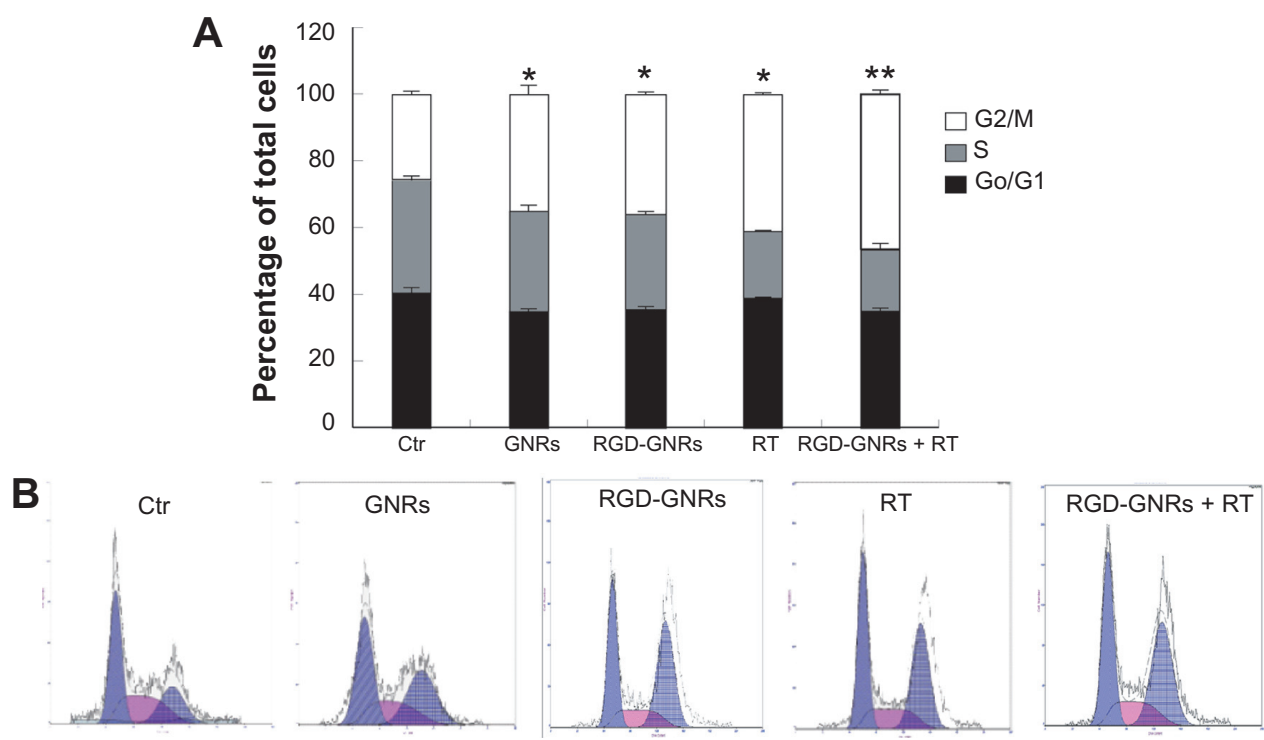

Figure 5 Enhancement of radiation-induced G2/M cell cycle arrest by RGD-GNRs in A375 cells. A375 cells were incubated with either Dulbecco's Modified Eagle Medium (controls), gold nanorods $(50 \mu \mathrm{g} / \mathrm{mL})$ for one hour, or RGD-GNRs $(50 \mu \mathrm{g} / \mathrm{mL})$ for one hour without or with irradiation $(6 \mathrm{mV} \mathrm{x}$-rays with a dose of $4 \mathrm{~Gy})$, and then the cells were stained with propidium iodide, and analyzed by flow cytometry 24 hours after radiation. (A) Percentage in different cell phases. Histograms represent the mean \pm standard deviation ( $n=3$ experiments). (B) Flow cytometry analysis for the different treatment groups.

Notes: $* P<0.05$ compared with the control group; $* * P<0.05$ compared with radiotherapy alone group.

Abbreviations: Ctr, Control Group; GNR, gold nanorod; RGD-GNRs, arginine-glycine-aspartate-conjugated gold nanorods; RT, radiotherapy.

due to the lack of the RGD receptor on the surface of the cell membrane, could take up few RGD-GNRs, ${ }^{26}$ so these molecules may be nontoxic to normal cells.

Our results show that RGD-GNRs were readily incorporated into the cells through integrin $\alpha_{v} \beta_{3}$-receptor-mediated endocytosis. RGD-GNRs as a sensitizer could enhance the response of radioresistant melanoma cells with a 1.35 dose modification factor. The mechanisms whereby RGD-GNRs enhanced the response to radiation were associated with multiple factors.

In the present study, RGD-GNRs or radiation alone resulted in an increase in the percentage of cells in the $\mathrm{G} 2 / \mathrm{M}$ phase of the cell cycle, while combining these two treatments had an additional effect of inducing the cells in the $\mathrm{G} 2 / \mathrm{M}$ phase. Because tumor cells are more radiosensitive in the G2/M phase and less so in the G0/G1 or S phase, ${ }^{27}$ increased radiation-induced cytotoxicity was seen following treatment of the cells with a combination of RGD-GNRs and radiation. Likewise, increased cell numbers in the G2/M phase could also explain some of the increase in susceptibility to radiation-induced DNA damage reflected by increased expression of the DNA repair protein, $\gamma \mathrm{H} 2 \mathrm{AX}$, compared with cells treated with radiation alone. ${ }^{28}$ Our results demonstrate that disruption of the cell cycle phases by RGD-GNRs might determine the relative radiosensitivity of A375 cells.

The radiosensitizing effect by RGD-GNRs might also be explained by inhibition of integrin $\alpha_{v} \beta_{3}$ expression.
A375 melanoma cells that overexpress the integrin $\alpha_{v} \beta_{3}$, show elevated levels of the protein following irradiation. RGDGNRs, which with the cells were preincubated, inhibited the expression of spontaneous and radiation-induced expression of integrin $\alpha_{v} \beta_{3}$ and presumably resulted in the sensitization of the cells to radiation (Figure 4). There are a number of pathways in melanoma cells that contribute to radiation resistance, one of which may involve integrin-stimulated pathways. It has been reported that the impact on cell survival and cell cycle progression in mammalian cells by irradiation is strictly controlled by integrin-mediated adhesion to extracellular matrix proteins and the binding of growth factors to their cognate receptors. ${ }^{29}$ Integrin-stimulated pathways are similar to and intimately coupled with those pathways triggered by growth factors, eg, vascular endothelial growth factor receptor 2 (VEGFR2). ${ }^{30}$ Some studies indicate that a direct interplay between $\alpha_{v} \beta_{3}$ and VEGFR-2 occurs at the biochemical level. ${ }^{30,31}$ High VEGFR2 induces a highly specific radioprotective effect toward $\alpha_{\mathrm{v}} \beta_{3}$ integrin-positive endothelial cells in the tumor; ${ }^{32}$ this results in promoting intrinsic radioresistance. On the other hand, radiation upregulates $\alpha_{v} \beta_{3}$ expression and activates Akt, the key antiapoptic protein kinase in endothelial cells, thus forming a defense mechanism and survival signal against radiation damage. ${ }^{9}$ This may account for the acquired radioresistance of tumor cells after radiotherapy. Therefore, inhibition of integrin $\alpha_{v} \beta_{3}$ survival signaling by RGD-GNRs may lead to the reversal 

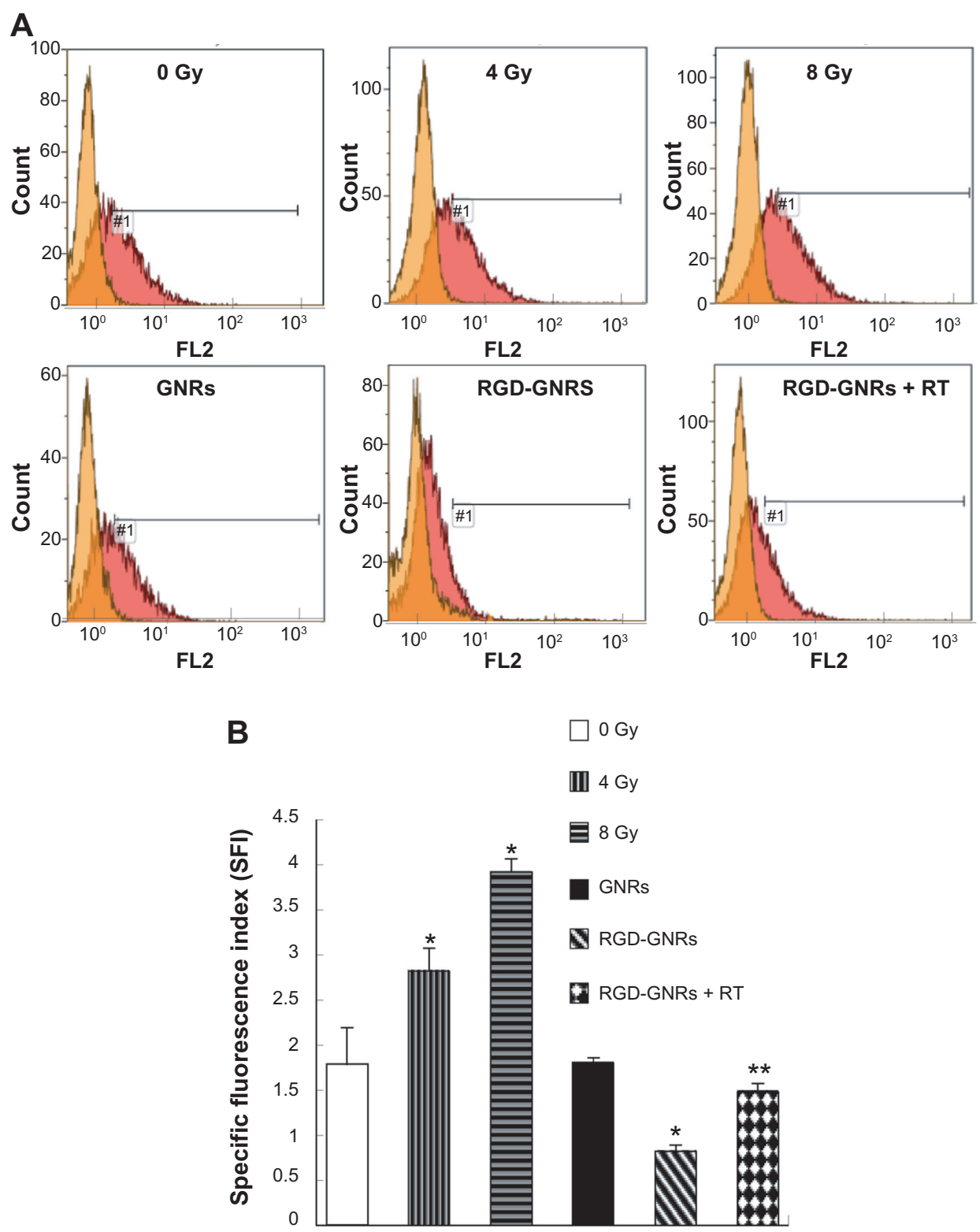

Figure 6 Changes in integrin $\alpha_{v} \beta_{3}$ expression level. (A) A375 cells were treated with either radiation, gold nanorods (50 $\mu$ g/mL) for one hour, or RGD-GNRs (50 $\mu$ g/mL) for one hour without or with irradiation, and then the cells were stained with anti-integrin $\alpha_{v} \beta_{3}$ antibody LM609 or isotype-matched control antibody DD7 24 hours after treatment and $\alpha_{v} \beta_{3}$ expression was measured by flow cytometry. (B) $\alpha_{v} \beta_{3}$ expression was quantified with specific fluorescence intensity; experiments were done in triplicates. Columns, mean from three repeated experiments; bars, standard deviation.

Notes: $* P<0.05$ compared with control group; ** $P<0.05$ compared with radiotherapy alone group.

Abbreviations: GNR, gold nanorod; RGD-GNRs, arginine-glycine-aspartate-conjugated gold nanorods; RT, radiotherapy.

of tumor cell resistance to radiotherapy, which is a way to enhance the antitumor effects of radiotherapy.

Gold nanorods not only serve as an RGD delivery system to improve selective binding to tumor cells and minimize damage to surrounding normal tissue, but also have other interesting properties, such as increasing the absorption of radiation energy and their preferential accumulation in cancer cells. $^{28,33}$ It has long been realized that the effect of a defined dosage is increased when a high- $Z$ material is in the targeted zone through a photoelectric effect, ${ }^{34}$ of which the enhancement is proportional to the amount of the high- $Z$ material. Nevertheless, most studies have focused on lowenergy radiation because materials with a high atomic number, such as gold, preferentially absorb kilovoltage x-rays. Megavoltage x-rays, used in the present studies, are more commonly used in the clinic, particularly for deep-seated tumors. Therefore, the radiosensitizing effect of $\mathrm{mV} x$-rays cannot be attributed to high- $Z$ materials alone. Roa et al reported $^{35}$ that one possibility, in agreement with present day data, is an interaction between gold nanorods and the 
cell cycle (Figure 5). Another possible mechanism is that gold nanorods, when irradiated in the cell, produce a high level of intracellular reactive oxygen species, which leads to elevated levels of oxidative stress and is manifested as an increased level of apoptosis compared with irradiation alone. ${ }^{36}$ An additional hypothesis proposed as a result of work in DNA plasmid models ${ }^{28}$ is that sensitization occurs due to short-range electrons produced by the interaction between gold nanorods and $\mathrm{mV} \mathrm{x}$-rays. The increased production of low-energy electrons close to the DNA causes more damage than radiation alone. Our data confirm that gold nanorods plus radiation induced more apoptosis and mitotic death in A375 cells than radiation alone, and also showed that this effect could be significantly enhanced by conjugating the gold nanorods to RGD.

In summary, we demonstrated that RGD-GNRs have remarkable potential to enhance radiotherapy of melanoma cancer cells. RGD-GNRs, in combination with $6 \mathrm{MV}$ irradiation, enhance the radiosensitivity of the cells. This radiosensitizing effect may be attributable to alterations in the capacity of the cell to resist apoptosis caused by RGD-GNRs, mainly through downregulation of radiationinduced $\alpha_{\mathrm{v}} \beta_{3}$ and arresting the cell cycle at the G2/M phase. Because the success of radiotherapy for patients with melanoma largely depends on tumor radiosensitivity, the combination of RGD-GNRs and radiation needs further investigation.

\section{Acknowledgments}

This article was funded by research grants (09JC411900, 09411951100, 08411960600) from the Science and Technology Commission of Shanghai and the National Natural Science Foundation of China (81171377), National Basic Research Program of China (2011CB707504, 2010CB933903). The authors thank Drs T FitzGibbon and E Mi for comments on the manuscript.

\section{Disclosure}

The authors report no conflicts of interest in this work.

\section{References}

1. Nam JM, Chung Y, Hsu HC, Park CC. Beta1 integrin targeting to enhance radiation therapy. Int J Radiat Biol. 2009;85(11):923-928.

2. Hynes RO. Integrins: bidirectional, allosteric signaling machines. Cell. 2002;110(6):673-687.

3. Hodivala-Dilke K. Alphavbeta3 integrin and angiogenesis: a moody integrin in a changing environment. Curr Opin Cell Biol. 2008;20(5):514-519.

4. Seftor RE. Role of the $\beta 3$ integrin subunit in human primary melanoma progression: multifunctional activities associated with $\alpha(\mathrm{v}) \beta 3$ integrin expression. Am J Pathol. 1998;153(5):1347-1351.
5. Monferran S, Skuli N, Delmas C, et al. Alphavbeta3 and alphavbeta5 integrins control glioma cell response to ionising radiation through ILK and RhoB. Int J Cancer. 2008;123(2):357-364.

6. Wick W, Wick A, Schulz JB, et al. Prevention of irradiationinduced glioma cell invasion by temozolomide involves caspase 3 activity and cleavage of focal adhesion kinase. Cancer Res. 2002;62(6):1915-1919.

7. Hallahan DE, Geng L, Cmelak AJ, et al. Targeting drug delivery to radiation-induced neoantigens in tumor microvasculature. $J$ Control Release. 2001;74(1-3):183-191.

8. Makrilia N, Kollias A, Manolopoulos L, Syrigos K. Cell adhesion molecules: role and clinical significance in cancer. Cancer Invest. 2009;27(10):1023-1037.

9. Abdollahi A, Griggs DW, Zieher H, et al. Inhibition of alpha(v) beta3 integrin survival signaling enhances antiangiogenic and antitumor effects of radiotherapy. Clin Cancer Res. 2005;11(17): 6270-6279.

10. Albert JM, Cao C, Geng L, Leavitt L, Hallahan DE, Lu B. Integrin alpha $\mathrm{v}$ beta 3 antagonist cilengitide enhances efficacy of radiotherapy in endothelial cell and non-small-cell lung cancer models. Int J Radiat Oncol Biol Phys. 2006;65(5):1536-1543.

11. Peer D, Karp JM, Hong S, et al. Nanocarriers as an emerging platform for cancer therapy. Nat Nanotechnol. 2007;2(12):751-760.

12. Wang T, Zhang X, Pan Y, et al. Fabrication of doxorubicin functionalized gold nanorod probes for combined cancer imaging and drug delivery. Dalton Trans. 2011;40(38):9789-9794.

13. Chen SH, Ji YX, Lian Q, et al. Gold nanorods coated with multilayer polyelectrolyte as intracellular delivery vector of antisense oligonucleotides. Nano Biomed Eng. 2010;2(1):15-23.

14. Zhang XQ, Pan BF, Wang K, et al. Electrochemical property and cell toxicity of gold electrode modified by monolayer PAMAM encapsulated gold nanorods. Nano Biomed Eng. 2010;2(3):182-188.

15. Pan B, Ao L, Gao F, et al. End-to-end self-assembly and colorimetric characterization of gold nanorods and nanospheres via oligonucleotide hybridization. Nanotechnology. 2005;16(9):1776-1780.

16. Murphy C, Jana N. Controlling the aspect ratio of inorganic nanorods and nanowires. Adv Mater. 2002;14(1):80-82.

17. Li X, Kao FJ, Chuang CC, He S. Enhancing fluorescence of quantum dots by silica-coated gold nanorods under one- and two-photon excitation. Opt Express. 2010;18(11):11335-11346.

18. Johnsson B, Löfås S, Lindquist $\mathrm{G}$. Immobilization of proteins to a carboxymethyldextran-modified gold surface for biospecific interaction analysis in surface plasmon resonance sensors. Anal Biochem. 1991;198(2):268-277.

19. Wiendl H, Mitsdoerffer M, Hofmeister V, et al. A functional role of hla-g expression in human gliomas: an alternative strategy of immune escape. J Immunol. 2002;168(9):4772-4780.

20. Yi DK. A study of optothermal and cytotoxic properties of silica coated Au nanorods. Mater Lett. 2011;15(65):2319-2321.

21. Li ZM, Huang P, Zhang XJ, et al. RGD-conjugated dendrimer-modified gold nanorods for in vivo tumor targeting and photothermal therapy. Mol Pharm. 2009;1(7):94-104.

22. Gormley AJ, Malugin A, Ray A, et al. Biological evaluation of RGDfKgold nanorod conjugates for prostate cancer treatment. J Drug Target. 2011;19(10):915-924.

23. Ferlay J. Age-standardised incidence rates from the GLOBOCAN 2008 database (http://www-dep.iarc.fr/) using World 2000 population as standard provided on request, 2010.

24. Tallury P, Payton K, Santra S. Silica-based multimodal/multifunctional nanoparticles for bioimaging and biosensing applications. Nanomedicine. 2008;3(4):579-592.

25. Zhan Q, Qian J, Li Xi, He S. A study of mesoporous silica-encapsulated gold nanorods as enhanced light scattering probes for cancer cell imaging. Nanotechnology. 2010;5(21):055704.

26. Yun GE, Bin K. Surface plasmon resonance scattering and absorption of biofunctionalized gold nanoparticles for targeted cancer imaging and laser therapy. Sci China Tech Sci. 2011;9(54):2358-2362. 
27. Sinclair WK. Cyclic $\mathrm{x}$-ray responses in mammalian cells in vitro. Radiat Res. 1968;33(3):620-643.

28. Zheng Y, Hunting DJ, Ayotte P, Sanche L. Radiosensitization of DNA by gold nanoparticles irradiated with high-energy electrons. Radiat Res. 2008;169(1):19-27.

29. Cordes N, Meineke V. Integrin signalling and the cellular response to ionizing radiation. J Mol Histol. 2004;35(3):327-337.

30. Mahabeleshwar GH, Feng W, Reddy K, et al. Mechanisms of integrin-vascular endothelial growth factor receptor cross-activation in angiogenesis. Circ Res. 2007;101(6):570-580.

31. Mahabeleshwar GH, Feng W, Phillips DR, Byzova TV. Integrin signaling is critical for pathological angiogenesis. J Exp Med. 2006;203(11):2495-2507.

32. Gorski DH, Beckett MA, Jaskowiak NT, et al. Blockage of the vascular endothelial growth factor stress response increases the antitumor effects of ionizing radiation. Cancer Res. 1999;59(14):3374-3378.
33. Chen W, Zhang J. Using nanoparticles to enable simultaneous radiation and photodynamic therapies for cancer treatment. $J$ Nanosci Nanotechnol. 2006;6(4):1159-1166.

34. Spiers FW. The influence of energy absorption and electron range on dosage in irradiated zone. Br J Radiol. 1949;22(261):521-533.

35. Roa W, Zhang X, Guo L, et al. Gold nanoparticle sensitize radiotherapy of prostate cancer cells by regulation of the cell cycle. Nanotechnology. 2009;20(37):375101

36. Geng F, Song K, Xing JZ, et al. Thio-glucose bound gold nanoparticles enhance radio-cytotoxic targeting of ovarian cancer. Nanotechnology. 2011;22(28):285101.

\section{Publish your work in this journal}

The International Journal of Nanomedicine is an international, peerreviewed journal focusing on the application of nanotechnology in diagnostics, therapeutics, and drug delivery systems throughout the biomedical field. This journal is indexed on PubMed Central, MedLine, CAS, SciSearch ${ }^{\circledR}$, Current Contents ${ }^{\circledR} /$ Clinical Medicine,
Journal Citation Reports/Science Edition, EMBase, Scopus and the Elsevier Bibliographic databases. The manuscript management system is completely online and includes a very quick and fair peer-review system, which is all easy to use. Visit http://www.dovepress.com/ testimonials.php to read real quotes from published authors. 